\title{
Integral Model of Strategic Management: Identification of Potential Synergies
}

\author{
Aleksandar M. Dejanović ${ }^{1}$, Slavka T. Nikolić ${ }^{2}$ Jelena Stanković \\ ${ }^{1}$ Modern Business School, Narodnih Heroja 30, 11070 Novi Beograd, Serbia, \\ email: aleksandar.dejanovic@mbs.edu.rs \\ ${ }^{2}$ Universtiy of Novi Sad, Faculty of Technical Sciences, Trg Dositeja Obradovića \\ 6,21000 Novi Sad, Serbia; e-mail: snikolic@uns.ac.rs, stankovicj@uns.ac.rs
}

Abstract: The main goal of this study is the construction of an integral model of strategic management, based on the comparative analysis among many well-established management concepts. It was found that new product development, total quality management (TQM), brand management and customer relationship management (CRM) share common characteristics such as strategic dimension, corporate culture dimension, customer focus, etc. Thus, the object of this paper refers to the potential of connection of these managerial concepts into a single Integral model of strategic management together with a measuring system based on Balanced Scorecard (BSC). After the relevant literature review and theoretical constructs on a conceptual level, the model has been tested in practice. The experiment has proved that the Integral model of strategic management is applicable and it positively impacts on a company's performance.

Keywords: Integral Model of Strategic Management; New Product Development; Total Quality Management; Brand Management; Customer Relationship Management

\section{Introduction}

In the field of strategic management, both in theory and practice, there are many well-established management concepts, models and techniques. Based on the comparative analysis, it was found that among them there are a lot of similarities. Thus, it was discovered that new product development, total quality management, brand management and customer relationship management share common characteristics such as strategic dimension, relying on corporate culture, customer focus, continuous improvement and measurability, i.e. manageability. These common features suggest the possibility of connection of these managerial concepts into a single integral model of strategic management.

The aim of this research is the construction and function of the integral model of strategic management which encompasses four identified elements: (1) New Product Development; (2) Total Quality Management-TQM; (3) Brand 
Management; (4) Customer Relationship Management-CRM. As one of the requirements of strategic management, a measuring system based on Balanced Scorecard-BSC has been installed into this model. All the mentioned elements are well-known in theory and practice, but their combination and cross-influence represent a novelty in the field of strategic management. Therefore, the construction of an integral model of strategic management of these concepts can be considered as a first-class theoretical and practical challenge.

The primary goal of this research is to demonstrate the functionality of the integral model of strategic management in real conditions. The goal of the research set in this way implies that the integral model is implemented in practice and its effects are measured (i.e. how it affects the organization's performance). According to the relevant literature review as well as the research results obtained in the experimental company, advantages and disadvantages of this model should be identified, and in this regard areas for progress and improvement should be defined. This research should also foster theoretical discussion and initiate new research as well as send a signal to companies that are ready to redefine their strategies.

The need for new solutions in strategic management is especially dominate during periods of economic crisis when most companies lose strategic orientation. Managers of these companies, as a response to the crisis, instinctively seek shelter, hoping the disturbances will not last for a long time. Integral model of strategic management has a completely different paradigm, which should be illustrated by the results of this research and therefore recommended for use in practice.

This paper is organized as follows. The first part presents the subject of this research in a wider context as well as related literature used for the construction of integral model of strategic management. The second part is devoted to model development. It describes its structure, basic characteristics and logic of functioning. Then, we introduce the research methodology used in this research, present the main findings, discuss the model implications and finally conclude our study with a proposal for further research.

\section{Theoretical Background}

Sudden and radical market trends constantly change market landscape. Old rules and "maps" quickly become obsolete. Therefore, during the past few decades, many new business models and concepts appeared in theory and practice. New solutions are mainly directed towards integrated management systems, which combine all the components of the business into a coherent whole. Their basic characteristic is that they can simultaneously realize common functions of associated subsystems, as well as achieve specific goals in accordance with the requirements of interested parties (stakeholders). 
The study of relevant literature reveals that there are a lot more papers on the integration of standardized management systems that integrate those management systems in accordance with standards such as ISO 9000, ISO 14000/EMAS, OHSAS 18000, HACCP/ISO 22000, ISO 27000 and SA 8000/ISO 26000. Among the first to start the study of this issue were: Miles and Russell [32], Dale and Wilkinson [11], Karapetrovic [28], Zutchi and Sohal [43], Jørgensen et al. [26], as well as Abrahamson, Hansson and Isaksson [1]. This "surge" has occupied the attention of academics but also managers in practice, which can be seen in a growing number of organizations, to have two or more valid certificates of compliance required by different standards. On the other hand, models for the integration of non-standardized management systems are quite neglected. In this way, the gap in the system of knowledge has been observed and this study was initiated.

According to models of integrated standardized management systems, the integral model of strategic management has been designed. This structured model includes: (1) New Product Development; (2) Total Quality Management-TQM; (3) Brand Management and (4) Customer Relationship Management-CRM. A measuring system based on Balanced Scorecard (BSC) has also been installed into this model.

By reviewing the relevant literature, it can be seen that all these elements have some common characteristics which enable them to be connected. Firstly, all of the business concepts that are connected in the model have a strategic dimension. Managing the development of a new product requires a foothold in the strategy [10], [8]. Recent studies have explicitly shown that companies which have clearly defined objectives in the strategy of new product development achieve significantly better results compared to competitors without strategic orientation [9]. The same can be concluded for the total quality management. This business philosophy also involves a strategic approach [15], [39], [36]. Successful brand management is also unthinkable with adequate strategies [29], [21]. Finally, consumer relationship management is a strategy, not sales tactics or technology sales [16], [35]. Therefore, each element of the integral model is part of the development of the organization in a time span of 3 to 5 years. Their implementation implies significant investment and engagement of resources, while requiring dedication, i.e. leadership of most responsible leaders in the company. Secondly, all of the business concepts that are integrated in the model have support in the corporate culture. For example, managing the development of a new product depends on an innovative climate within the company, and that innovative climate is the reflection of the corporate culture [25]. The total quality management system is based on solid documentation, written rules - the rules stemming from the corporate culture [23], [34]. Likewise, corporate culture determines invisible brand elements [42]. Finally, corporate culture is directly dependent on the quality of the relationship between companies and customers [38], [24]. Thirdly, every business concept in the model is directed towards 
consumers. When new products are being developed, the requirements, needs, desires and expectations of consumers are the starting point [4], [41]. Also, one of the fundamental principles of total quality management to be met is fulfilling and overcoming consumer expectations. Within this theoretical context, a specific technique has been developed, QFD (Quality Function Deployment), which serves to "translate" the demands of consumers into technical, i.e. product specifications. According too many authors, this technique is one of the most important TQM tools [2], [17], [7]. Brand management is by definition customer orientated [13], [40] as well as CRM [18], [19], [22].

Based on a thorough review of the relevant literature, it was found that all elements that make the integral model of strategic management have their theoretical and practical pedigree. Studying the basic characteristics of the selected elements it was observed that there are a lot of similarities among them (strategic dimension, corporate culture dimension and customer focused orientation), which reveals the possibility of their interconnection. With the respect to the current management literature, this study extends recent work in the field of strategic management and advocates for the synchronization of wellknown business concepts: new product development management, total quality management, brand management and customer relationship management. Focusing on these theoretically compatible managerial concepts, together with the measuring system based on balanced scorecards, we have coordinated them and merged them into a single integral model of strategic management.

\section{Construction of Integral Model of Strategic Management}

Integral model of strategic management proposes the integration of four selected elements and a measuring system. Each element has its own identity that makes it special and different from the others. These specific features, i.e. the differences are preserved in the model. It is important that these differences are not too distinct that they are not irreconcilable, but rather complement each other. Differences contribute the model to be richer, more layered, more dynamic, but also more complex and unstable. On the other hand, concerning integral model there are many mutual characteristics and similarities between the elements. Cohesion and sustainability of this model are built on that.

Architecture of the integral model of strategic management does not have pyramidal shape, because in this model the elements are not arranged according to hierarchy. Relations between the elements are not based on superiority, or inferiority. In this model there are no important and less important elements. Their roles are different but equal. Minimization of any element would significantly diminish the basic idea of functioning of integral model of strategic management. Such a hypothetical configuration can best be shown by Venn diagram: 


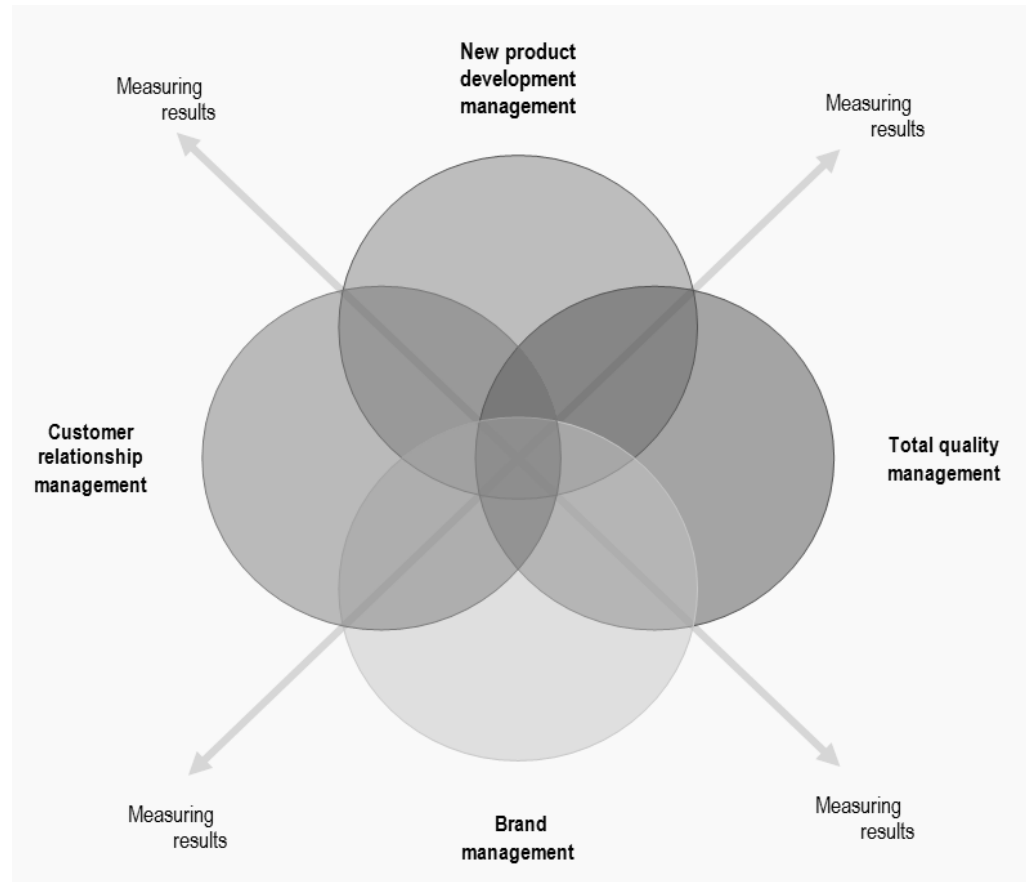

Figure 1

Construction of the integral model of strategic management

It should be emphasized that an integral model of strategic management is not a simple sum of the four mentioned elements. The construction of this model is not mechanical, i.e. mathematical. The model cannot be obtained by placing the elements one upon the other. It is not possible, because each individual element is in fact very jagged, complex in its structure and has a different shape. If all the elements were connected only on the basis of simple addition, "mega" model would occur, which would be very bulky, complicated, confusing and difficult to manage. Such a model would be unsuitable for the application and also unstable. In this context the fundamental question arises - how to construct the model and adapt it to the needs of a company. This question may be set up differently - how to "pack" four complex elements in the appropriate form and guide, i.e. synchronize their operation. This can be achieved by extracting the essence out of each element. This will provide a number of key components - basic characteristics of each concept that can be easily combined. Again, it is important to emphasize that these extracts do not add up, but mix and would result in a "recipe", i.e. the proportion of individual components depends on the specific needs and characteristics of a company. 


\subsection{Basic Characteristics of Integral Model of Strategic Management}

The first element - New product development - is specific because it has in its essence a creative process that starts with an idea and ends with the launch of a new product on the market. Its basic characteristic is creativity [6], [20]. This creativity is embedded in a formalized and structured algorithm in order to manage the creative process, but this does not change the substance. The most important part of the new product development is stimulation of new ideas, choice of high potential ideas and their conversion into new products and services intended for the market in the most efficient way [30]. Companies that do not want to copy or imitate their competition cannot survive without creativity. In addition, this creativity has to be focused on the needs, requirements, desires and expectations of customers.

The second element - Total Quality Management - implies quality improvement in a company on the basis of process and system approach [5]. In this sense, the importance of documentation is emphasized (policies, plans, procedures, instructions, records), responsibilities identification, constant comparison with established specifications and remove non-conformities [3]. According to this, it can be concluded that the basic characteristic of quality management is administrative and organizational orderliness. It is necessary for every business system. A company that does not have developed organizational and administrative infrastructure can achieve accidental short-term success. Probability for such a company to achieve set goals can be compared to probability in games of chance.

The third element - Brand management - has many dimensions, but it is mostly focused on the presentation of the company and its products. Brand reflects the exterior (visible elements), but also the personality, i.e. the character of the company (invisible elements). Visible elements are first to be detected and they create the impression, and the invisible elements complement this impression and can cause deeper psychological reactions of customers [12]. This way brand essence is expressed: particularity/uniqueness. It is the foundation on which its position is built and strengthened in customers' minds [37]. Strong brand strengthens the company, encourages its development and ensures competitive advantage. On the other hand, a weak brand is a handicap for the company, as it reduces its chances for development. In such circumstances, the company is doomed to anonymity and is usually referred to as "other". These companies are forced to fight for survival by lowering of costs and low prices. Wherein, there is a limit to which costs can be reduced without threatening the functioning of the company. Therefore, brand management. i.e. the reaction, maintenance and improvement of its particularity and uniqueness represents the imperative in modern business. 
The fourth element - Customer relationship management - includes the interaction between the company and customer in which values are created and exchanged [33]. Through this interaction, the relations between company and customer are established, maintained and improved. The essence of this relationship is mutual confidence. Of course, in addition to confidence among companies and customers a whole range of relationships is created (affection, understanding, respect) but without confidence, as the key component, the overall relationship will be destroyed [31]. The creation of confidence implies the respect of the obligations taken on and represents one of the fundamental elements of perception of customers towards the companies, i.e. brands. It takes time to build it, but can be lost fast. If it is once lost, it is difficult to be re-built. Therefore, in order to be successful on the market a company has to go through the phase of gaining customers' confidence.

Hence, creativity, administrative and organizational orderliness, particularity/uniqueness and confidence, as basic characteristics of elements were built in the integral model of strategic management.

Creativity is built into the integral model through new product development. Quality management brings administrative and organizational orderliness to the company, while brand management entries particularity and uniqueness. Thanks to customer relationship management the company gains confidence (Figure 2).

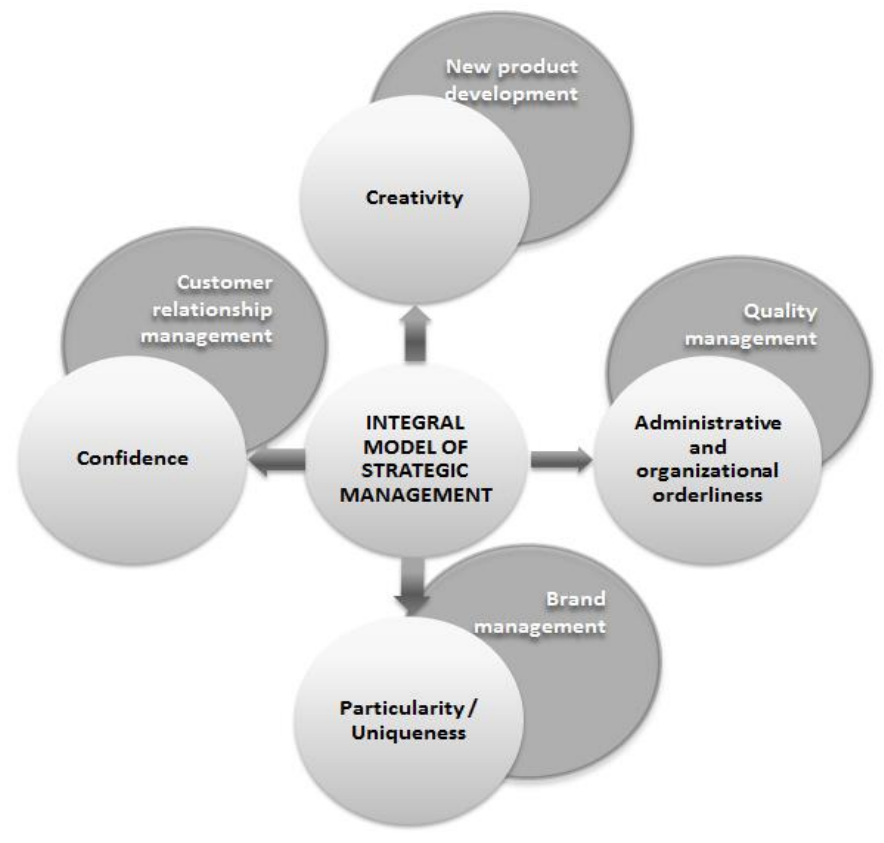

Figure 2

Basic Characteristics of the Integral Model of Strategic Management 
Different characteristics of the elements that make up an integral model of strategic management determine its functioning. These characteristics should not be viewed in isolation, but through interaction. Greater degree of compatibility guarantees more harmony in the functioning of integral models, and vice versa lower compatibility of characteristics causes more imbalances. However, dynamic models necessarily have imbalance in themselves. Internal differences drive models. Strategic development management based on any model involves conflict and harmony, which is imbalance and restoration at a higher level.

\subsection{Integral Model of Strategic Management - Circle of Functioning}

The basic attributes of each element indicate what the integral model of strategic management looks like, but they also determine the way it functions. Activities can be presented in the form of a circular flow starting from the creative phase up to the measurement of results, i.e. planning a new cycle.

The circular flow of activities in integral model of strategic management resembles helio-centric system (Figure 3). However, the focus of this model is the customer. ${ }^{1}$ All of these activities "revolve" around this center in order to establish, support and promote the organization's relationship with customers. If any of these activities goes out of this orbit and loses its focus on the customer, then the model will function eccentrically. In the extreme case, if the centrifugal forces in the company are so strong (resistance to change) and move away the activities from this center, the model will disintegrate.

The logic of this model is linking of various processes and functions of the organization. The cycle begins with a creative impulse (first sequence Create/Innovate). Development of a new product begins, process or organization is improved. Something new is created. In the second sequence, this creative energy fits into the appropriate structure (TQM). This system, with its own rules, must not "choke" or obstruct creativity, but only direct it to appropriate standards as customers demand or expect it. After all, the first principle of quality management systems according to the ISO 9000 is the focus on the customer. In addition, thanks to the developed documentation basis of the quality system, the company receives administrative and organizational orderliness. The third sequence (Brand) involves fitting a new product or innovation in brand architecture in order to strengthen the brand, add it a new content, define new or confirm existing brand promise. In this way, a brand broadcasts a new or updated message to customers. In the following sequence the emphasis is on CRM activities.

1 That is why this model is in Anglo-american literature often called "Customer Centric". Some authors use the term "Customer Focused". There is no significant difference between these terms [14]. 


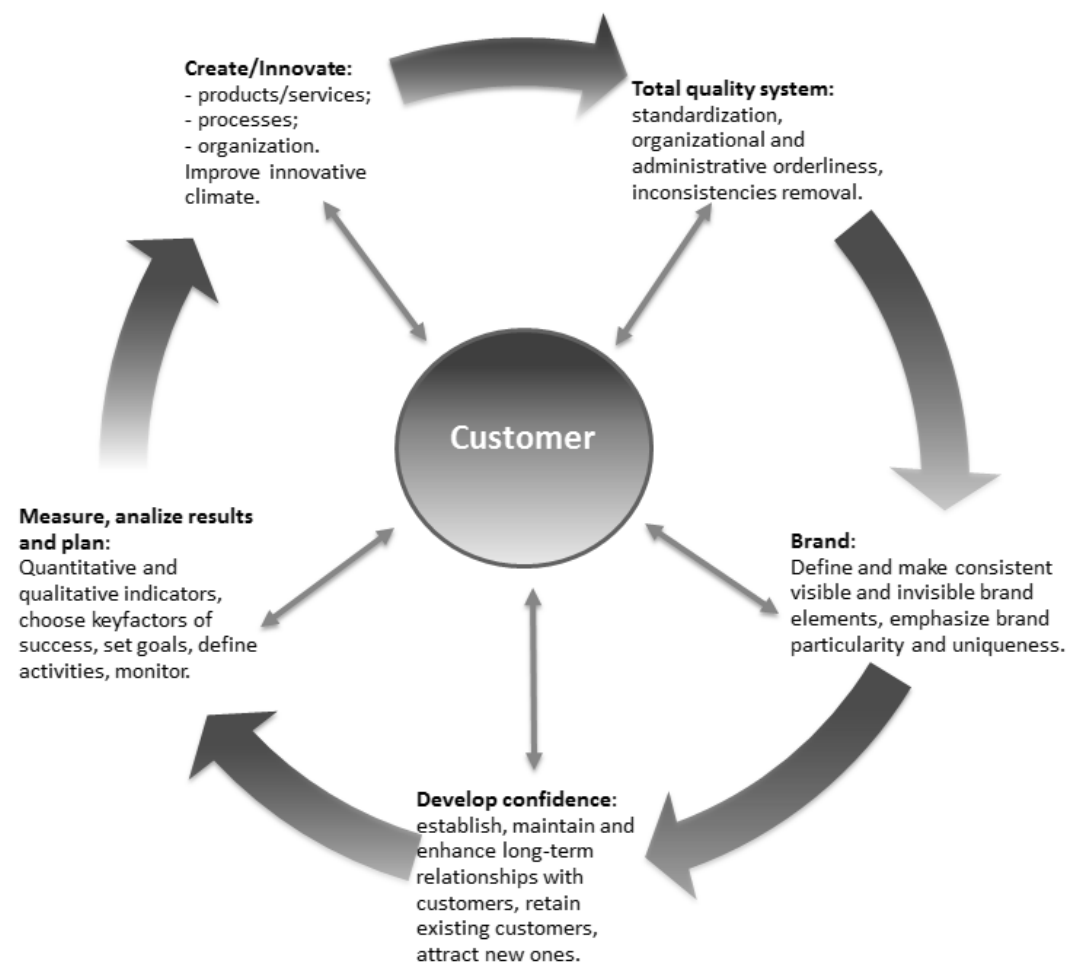

Figure 3

Integral Model of Strategic Management - Circle of Activities

All that has been done in previous phases merges with the activities aimed at establishing, maintaining and developing the relationship with customers. At the same time, insisting on confidence strengthening is a key component of the relationship between company and customers. Finally, measurement of company performance follows based on the BSC methodology, analysis and formulation of conclusions, lessons, making plans to improve the next cycle. Such an interpretation is reminiscent of Deming cycle or as in theory also called PDCA cycle (Plan; Do; Check and Act).

\section{Research Methodology}

The main hypothesis set in this research is that the integral model of strategic management has a positive impact on company performance. This hypothesis was tested in an experiment which was carried out under real market conditions during the period 2011 - 2013. So, measurements have lasted for three years, and in the field of research the BSC measurement system was used which involved five 
perspectives of structured model and a total of 21 key performance indicators (KPI):

- Perspective of creativity;

- Perspective of quality;

- $\quad$ Perspective of brand strength;

- $\quad$ Perspective of customers;

- Financial perspective

The perspective of creativity, in most of its features, matches the perspective of learning and growth in the original Kaplan Norton model [27]. It shows the level of development of innovative climate in the company, or creative and intellectual capacity of the company. Within this perspective four key performance indicators are defined: (1) Employee satisfaction; (2) Training and education of employees; (3) Investment in technological development; (4) Degree of automation. The first two indicators are related to human resources and the other two on technical and technological resources. These indicators reflect the company's ability to learn and progress.

The perspective of quality is broad and shows the state of the quality system of the company. However, this perspective focuses on processes, and administrative or organizational orderliness of the company. In this regard, the following key indicators are determined: (1) the process compliance with the requirements of ISO 9001:2008; (2) the quality of products; (3) quality of service; (4) implementation of service support as an important component of quality. This perspective represents the novelty, because it is not provided in the Kaplan-Norton model, and it was developed according to the needs of the integral model of strategic management. Identified indicators were chosen because each of them strongly reflects the level of development and characteristics of the quality system in organization.

Perspective of brand strength illustrates the position and prospects of the brand in the market. In this context four key performance indicators were defined: (1) investments in advertising; (2) an internet presentation as a channel of communication; (3) participation in social networks; (4) expression of corporate social responsibility. This perspective also represents original contribution to the Kaplan-Norton model. The first indicator was chosen because investment in advertising contributes to building a strong brand, "nourishes and refreshes" the brand in the minds of users. The second and third indicators reflect the growing importance of the Internet and social networks (Facebook) in brand development. The fourth indicator (Corporate Social Responsibility - CSR) illustrates the relationship between the company and community, which is an important component of a brand. 
The perspective of customers shows how customers perceive the company, and reveals a wide range of relationships between companies and customers, as defined by Kaplan-Norton model. Key performance indicators in this view are: (1) customers' satisfaction; (2) customers' loyalty; (3) the volume of sales; (4) the profitability of sales. Logically, each of these indicators convincingly testifies about the quality of the relationship between businesses and customers, in both qualitative and quantitative manner.

Financial perspective gives an insight into the financial impact of implemented changes in the company. Key performance indicators that monitor the financial perspective are: (1) collections; (2) payments; (3) structure of income; (4) structure of liabilities; (5) financial results. Based on Kaplan-Norton model, these five identified indicators, with high level of reliability, can assess financial condition of the company.

Key performance indicators have been chosen based on goals set in the strategic company plan, which is thoroughly consistent with the theoretical assumptions, referring to recommendations of Kaplan and Norton [27]. These indicators clearly and precisely show how far a company is from the defined strategic goals. Apart from that, the previously mentioned indicators are incorporated into a strategic map that links the activities and goals of a company. Due to that, a company can convert its initiatives and resources (tangible and non-tangible) into results. Using this measuring system, in other words control of strategy implementation, a company gets an opportunity to discover deviations in functioning of the integral model of strategic management very early and take corrective measures beforehand.

The number of key performance indicators is based on company practice in applying the BSC system. Namely, practice has shown that less than 15 indicators are not enough to show the whole picture of the company, and that more than 25 indicators complicate the monitoring and control too much. Therefore, commonly between 20 and 25 indicators are picked, as it was the case during the realization of this research.

According to the plan of the research, measurements are realized in company named "Positive" in Novi Sad, Serbia. This company was founded at the beginning of year 2000 and deals with selling computers and computer equipment, designing and production of complex computer networks, also technical support which is maintenance of IT equipment and installations. The company had 28 employees in its private property at the end of 2013. "Positive" company has been chosen as a partner in this research for the following reasons: (1) this company has implemented the integral model of strategic management; (2) the company uses the BSC software, which represents an important precondition for realization of the research; (3) the company has standardized its business with ISO 9000 and ISO 27000 standards which has been confirmed by valid certificates; (4) in this company an innovative environment has been made due to continual investments 
in professional training of employees, then growth and successful adaptation of technical and organizational improvements.

The research achieved was very complex. "Positive" company was first supposed to implement the integral model of strategic management. This model was introduced in the second half of 2010. A solid base for introducing this model was the existing organizational culture and managing system in the company. The dominant type of organizational culture (task culture) suited the realization of this experiment. Everything has been subordinated to problem solving, in other words to realization of projects and tasks, and emphasis has been set on getting results. Team type or in other words project type of work has been affirmed. Power in the company has been decentralized, because some individuals had high deciding autonomy thanks to their competence. Communication between the employees has become open and informal. Organizations in which this type of culture is dominant don't have pronounced organizational boundaries, they are very flexible and are ready for changes. Managing system of the company has been based on managing logics that is consistent to the demands of ISO 9001:2008 standards.

The first step in implementation of integral model of strategic management into "Positive" company was shaping the developing strategy for the 2011-2013 period. Within that, the position of the company was analyzed, and then new visions and missions were defined, as well as key values that the company would believe in and insist to affirm. In the second phase the main strategic choices and basic goals of the company were defined. These goals were grouped into five perspectives, according to the logics of the integral model of strategic management. After that, in the third phase, a measuring system was constructed, key performance indicators were chosen and a reporting system was set. That gave a possibility for following, supervision and control of integral model functionality. During the observed period, data were collected and the accomplished results were analyzed, along with the constant consultations with the company management.

Data were derived from the information system of the chosen company, using modern software tools, especially software package Business Navigator ver. 2:37, which is based on OLAP (Online Analytical Processing) technology. This software, for its basic characteristics and logics is one of the Balanced Scorecard applications because it combines several different (mutually connected) modules such as financial management, procurement and sales, production management, human resources management, marketing management, etc.

Measurements of the achieved results are realized simultaneously with the implementation of the model (beginning of 2011). Decreasing three-year trend of basic business indicators would be a reliable signal to show that an integral model of strategic management is not fulfilling its purpose. However, the increasing trend would point to a conclusion that this model affects the improvement of company performance (accepting the hypothesis). Fluctuation of trend (change of 
direction) would show that the long-term phenomenon trend would not be stable and in this case reliable conclusions on the functioning of the integral model could not be established, i.e. the hypothesis accepted or rejected.

\section{Results}

Completed research confirmed the hypothesis set in the plan of the research. The results of the experiment, i.e. analyses of data on the basis of measurement of three-year period (2011-2013), have shown that the integral model of strategic management is functional, i.e. that it influences the improvement of company performance. Most of the selected key performance indicators that are defined in the BSC measurement system convincingly testify in favor of this conclusion (Table 1).

Table 1

Key Performance Indicators in BSC Measuring System

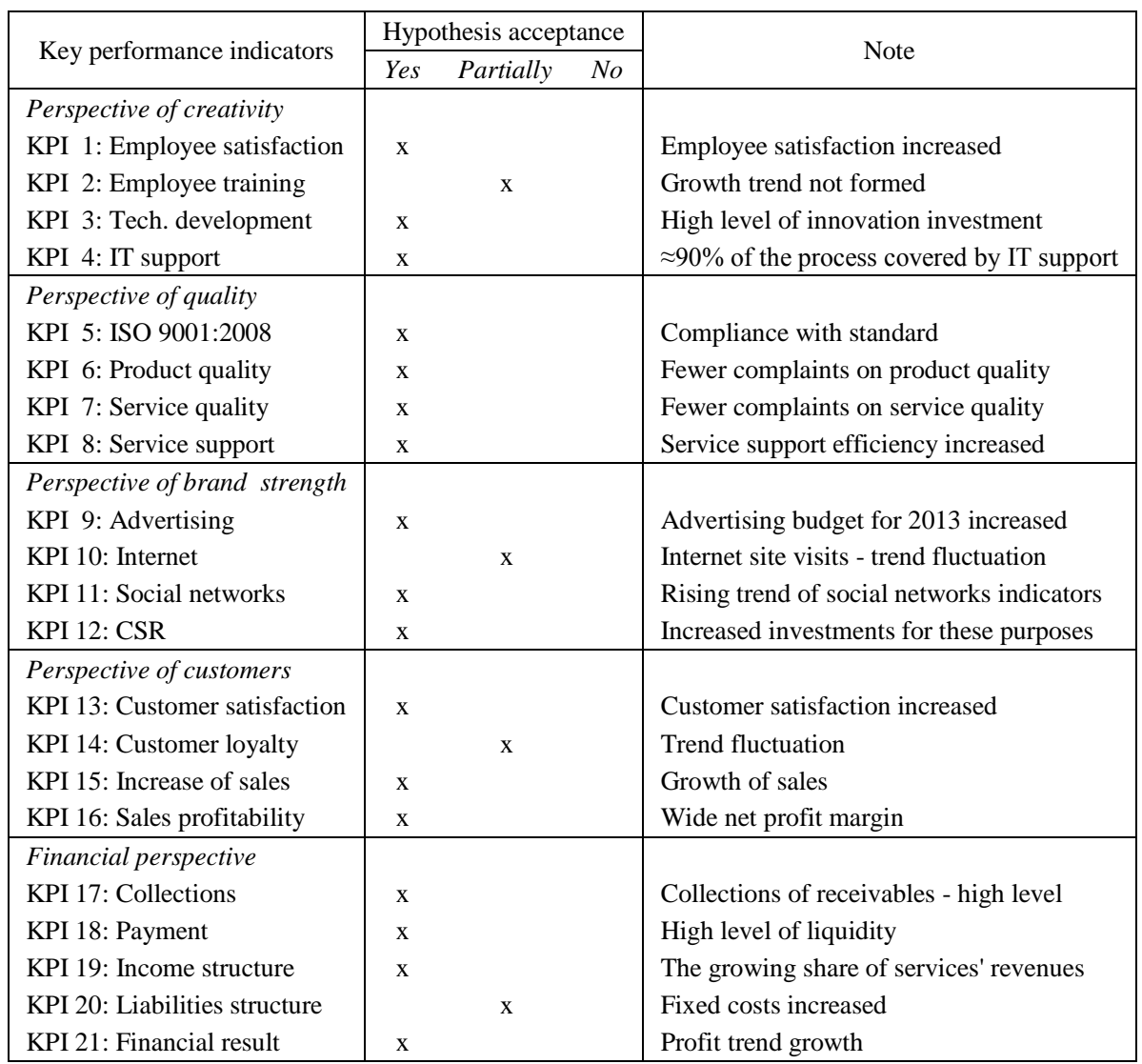


Most of the identified key performance indicators (17 from 21) fully confirm that company has improved its operations in the observed three-year period. In such a way, the hypothesis set in the plan of the research was validated. On the other hand, only 4 key performance indicators signal that the integral model of strategic management did not fully meet expectations (these indicators partially confirm the hypothesis).

Particularly conclusive proofs of successful functioning of integral model of strategic management are: (1) employee satisfaction; (2) compliance with standards ISO 9001:2008; (3) increased customer satisfaction; (3) financial result.

Employee satisfaction is one of the most important indicators in the integral model of strategic management. This importance is emphasized in all four elements that make the model. Concerning the first element (new product development) employees' role is mostly expressed through creativity, which is essential in the development of new products. The second element (TQM) involves active participation of employees at all levels in building quality management system. Also, one of essential principles of TQM is team work, which requires good interpersonal relations in the organization. Likewise, the TQM insists on intensive training and education of employees. The third element (brand management) relies on human factor too. In the fourth element (CRM) employees' role cannot be omitted. Finally, in BSC measurement system (embedded in integral model of strategic management) a specific perspective referring to measurement and monitoring of the results achieved in this area was developed. In the observed company, in which the model of strategic management was installed, employee satisfaction was assessed annually on the basis of a questionnaire. The questionnaire covered $87,1 \%$ of employees in 2011 and a year later $96,6 \%$ but in 2013 all employees completed it. Employee satisfaction increased from 8,96 in 2011 to 9,30 in 2013. High average grades of employees indicate that the company managed to create good conditions in the workplace, a good atmosphere at work, to motivate employees and encourage them to achieve the vision and goals of the company.

Compliance with international quality standards ISO 9001:2008 is expressed on the basis of quarterly internal audits of the quality system. According to internal audits reports, most of the non-conformities were recorded in 2011 and in the next two years the quality system of the company was greatly improved. In addition, it should be noted that out of total 12 internal audits, this system received the highest score (10) five times, four times it was graded "nine" and just three times by "eight". There were no scores lower than 8 , and the average score in this period was 9,2 .

Customer satisfaction, in this research, was measured through the questionnaires which included six important segments: a) retail offer; b) Internet sales offer; c) effectiveness in complaints resolving; d) the expertise of the sales staff and employees who are engaged in after-sales support; e) friendliness of the staff and 
f) price. Customers evaluated each of the above segments from 1 (lowest satisfaction) to 5 (highest satisfaction). Questionnaires have shown that each year better results were reached. In 2011 grades were, on average, lowest $(3,94)$. Customers were least satisfied with the price $(3,30)$ and retail offer $(3,54)$. On the other hand, they showed the highest level of satisfaction due to kindness of the staff. During the next year, customer satisfaction was significantly improved, as the average grade was 4,33 . Compared to the previous year, in 2012 based on 5 out of 6 selected criteria the grades were improved. Thereby, the maximum increase rate was related to the Internet and retail sales. However, the best results were accomplished in 2013 (average grade even 4,57). According to customers' grades resolving complaints was further enhanced, professional customer support and kindness of the staff, too. Customers have even shown a higher degree of price satisfaction.

Finally, the results achieved in creativity perspective, quality perspective, brand perspective and consumer perspective are reflected in the financial performance or financial results. After the implementation of the integral model of strategic management, it was noticed that there were consistently increased revenues and expenditures. During the reporting period, revenues increased by $13,2 \%$ and expenditures by $12,6 \%$. However, the achieved positive financial result considered in absolute amounts compared to the total turnover, as well as, in relation to the assets, does not show high profitability. For example, Return on Assets (ROA) in 2011 was only about $1,8 \%$. This means that every 100 RSD of engaged assets made only 1,8 RSD profit. In the following year this indicator remained unchanged, but by the end of 2013 it reached the level of about $2 \%$. Reviews of low profitability can be confirmed by the rate of net income (net income/sales revenue). This indicator, at the end of 2011 was only $0,72 \%$, in the following year $0,82 \%$, and at the end of 2013 it was $1,20 \%$. Such low values indicate that only a small portion of sales revenue go into profit (the largest portion of sales is burdened with expenses, indicating a lower level of cost-effectiveness). Slightly different picture is obtained on the basis of the rate of Return on Equity (ROE). In 2011 , this ratio stood at 10,2\%, in the following year 10,8\% and in 2013 at $14,2 \%$ which is quite high in comparison to the very successful companies. This indicator illustrates that the observed company with a relatively small capital runs a significant volume of turnover and makes profit (every 100 RSD of capital invested in 2013 makes 14 RSD of profit).

Based on such review, it can be concluded that the company is more successful after applying the integral model of strategic management. It should be noted that the model was implemented at a time when the global economy was not recovered from the deep recession. Economic conditions in Serbia were also very unfavorable. So, these good results cannot be attributed to random, or a positive effect of external factors, but primarily to internal factors of the company (efficient strategy, organizational solutions, innovation, flexibility, knowledge and energy of management and employees). 


\section{Conclusions}

Regarding the relevant literature studied, it was found that among many modern management concepts there are a lot of similarities, which reveals the possibility of their interconnection. In this analysis, it was concluded that new product development management, total quality management then brand management and customer relationship management are theoretically compatible management paradigms that can be synthesized into a unique integral model of strategic management. In addition, measuring system based on balanced scorecard has been installed into this model, thus significantly contributing and expanding the frames of current literature on strategic management.

The primary purpose of integral model of strategic management is to make a positive impact on company performance. In this sense, the hypothesis in this research was defined, which was verified based on the experiment under real market conditions over the period of 2011-2013. Measurements showed that the integral model of strategic management is functional and influences the improvement of company performance.

Integral model of strategic management is a possible answer to the fragmentation of business concepts. It was not formed under the influence of one author or a business school, but as a result of many different cross-influences. It is complex in its structure (comprising four elements and a measuring system), but it is essentially simple, practical and applicable, which is confirmed by the experiment conducted with the company "Positive". It is similar in its characteristics to other business ideas, but at the same time different from them because it has its own, separate logic. It can be an evolution (bring continuous improvements), but can cause disruption in the balance of the company by introducing revolutionary changes. It is not elaborated in detail and does not offer ready-made solutions, but it has clear principles that represent a strategic roadmap for the company. In other words, its flexibility leaves enough space for the company to adapt it to its needs. To the authors' best knowledge, this study is the first to perform integral model of strategic management which contains four different, but compatible concepts with BSC as a measuring system. It contains creativity (new product development), process approach, administrative and organizational orderliness (TQM), emotions (through brand management) and respect for the consumer (through CRM). Ethical standards must necessarily be incorporated because it relies on the corporate culture. This study has discovered a number of areas where identified concepts overlap, but also complement and stimulate better results, thus identifying possible improvement fields and translating that potential into real synergy.

\section{References}

[1] Abrahamsson, S., Hansson, J., \& Isaksson, R. (2010) Integrated Management Systems - Advantages, Problems and Possibilities. 
Conference paper - $13^{\text {th }}$ Toulon-Verona Conference: Organizational Excellence in Service

[2] Akao, Y. (1990) Quality Function Deployment: Integrating Customer Requirements into Product Design. Productivity Press

[3] Anjard, R. P. (1998) Total Quality Management: Key Concepts. Work Study, 47 (7) 238-247

[4] Bailetti, A. J., \& Litva, P. F. (1995) Integrating Customer Requirements into Product Design. Journal of Product Innovation Management, 12 (1) 315

[5] Bennett, L. M., \& Kerr, M. A. (1996) A System Approach to the Implementation of Total Quality Management. Total Quality Management, 7 (6) 631-665

[6] Boden, M. A. (1998) Creativity and Artificial Intelligence. Artificial Intelligence, 103 (1-2) 347-356

[7] Chan, L. K., \& Wu, M.-L. (2002) Quality Function Deployment: A Literature Review. European Journal of Operational Research, 143 (3) 463-497

[8] Cooper, R. G. (1984) How New Product Strategies Impact on Performance. Journal of Product Innovation Management, 1 (1) 5-18

[9] Cooper, R. G., \& Edgett, S. J. (2010) Developing a Product Innovation and Technology Strategy for Your Business. Research Technology Management, 53 (3) 33-40

[10] Crawford, M. C. (1972) Strategies for New Product Development. Business Horizons, 15 (6) 49-58

[11] Dale, B. G., \& Wilkinson, G. (1999) Integrated Management Systems - an Examination of the Concept and Theory. The TQM Magazine, 11 (2) 95104

[12] Davidson, H. (1997) Even More Offensive Marketing - an exhilarating action guide to winning in business. Penquin Books Ltd

[13] de Chernatony, L., \& McDonald, M. (1998) Creating Powerful Brands in Consumer, Service and Industrial Markets $\left(2^{\text {nd }}\right.$ ed.) Butterworth Hainemann Limited

[14] Fader, P. (2012) Customer Centricity: Focus on the Right Customers for Strategic Advantage. Wharton Digital Press

[15] Garvin, D. (1988) Managing Quality: The Strategic and Competitive Edge. The Free Press

[16] Gordon, I. (2001 September-October) CRM is Strategy, Not a Tactic. Ivey Business Journal 
[17] Griffin, A., \& Hauser, J. R. (1993) The Voice of Customer". Marketing Science, 12 (1) 1-27

[18] Grönroos, C. (1994) Quo Vadis, Marketing? Toward a Relationship Marketing Paradigm. Journal of Marketing Management, 10 (5) 347-360

[19] Gummesson, E. (1999) Total Relationship Marketing: Rethinking Marketing Management. A Butterworth-Heinemann

[20] Higgins, L. F. (1999) Applying Principles of Creativity Management to Marketing Research Efforts in High-Technology Markets. Industrial Marketing Management, 28 (3) 305-317

[21] Holt, D. B. (2003) Brands and Branding. HBS Publishing

[22] Injazz, C. J., \& Popovich, K. (2003) Understanding Customer Relationship management (CRM): People, process and technology. Business Process Management Journal, 9 (5), 672-688

[23] Irani, Z., Beskese, A., \& Love, P. (2004) Total Quality Management and Corporate Culture: Constructs of Organisational Excellence. Technovation (24), 643-650

[24] Iriana, R., \& Buttle, F. (2006) Customer Relationship Management (CRM) System Implementations: An Assessment of Organisational Culture. The International Journal of Knowledge, Culture and Change Management, 6 (2) $137-147$

[25] Isaksen, S. G., \& Akkerman, H. J. (2011) Creative Climate: A Leadership Lever for Innovation. Journal of Creative Behaviour, 45 (3) 161-187

[26] Jorgensen, T. H., Mellando, M. D., \& Remmen, A. (2006) Integrated Management Systems - Three Different Levels of Integration. Journal of Cleaner Production, 14 (8) 713-722

[27] Kaplan, R. S., \& Norton, D. P. (1992) The Balanced Scorecard - Measures That Drive Performance. Harvard Business Review, 70 (1) 71-79

[28] Karapetrovic, S. (2003) Musings on Integrated Management Systems. Measuring Business Excellence, 7 (1) 4-13

[29] Keller, K. L. (1997) Strategic Brand Management - Building, Measuring and Managing Brand Equity ( $1^{\text {st }}$ ed.) Prentice Hall

[30] Koen, P. A., Ajamian, G. M., Boyce, S., Clamen, A., Fisher, E., Fountoulakis, S., et al. (2004) Fuzzy Frond End: Effective Methods, Tools and Techniques. In P. Belliveau, A. Griffin, \& S. Somermeyer, The PDMA Toolbook for New Product Development. New York: John Wiley \& Sons

[31] Ljubojević, Č. (2002) Marketing usluga. Novi Sad: Stylos

[32] Miles, M. P., \& Russell, G. R. (1997) ISO 14000 Total Quality Environmental Management: the Integration of Environmental Marketing, 
Total Quality Management and Corporate Environmental Policy. Journal of Quality Management, 2 (1) 151-167

[33] Newell, F. (2000) Loyalty.Com: Customer Relationship Management in the New Era of Internet Marketing. McGraw Hill

[34] Nikolić, V., \& Nastasić, A. (2010) Organizational Culture as Significant Factor in Implementation of TQM - Experience in Serbian Economy. International Journal for Quality Research, 4 (1) 59-69

[35] Payne, A., \& Frow, P. (2005) A Strategic Framework for Customer Relationship Management. Journal of Marketing, 69, 167-176

[36] Prajogo, D. I., \& Sohal, A. S. (2006) The Relationship between Organization Strategy, Total Quality Management (TQM) and Organization Performance - the Mediating Role of TQM. European Journal of Operational Research (168) 35-50

[37] Ries, A., \& Trout, J. (1986) Positioning - The Battle for Your Mind. New York: McGrow Hill

[38] Rigby, D. K., Reichheld, F. F., \& Schefter, P. (2002) Avoid the Four Perils of CRM. Harvard Business Review, 80 (2) 101-109

[39] Schonberger, R. J. (1992) Is Strategy Strategic: Impact of Total Quality Management on Strategy. Academy of Management Executive, 6 (3) 80-87

[40] Schultz, D. E., \& Barnes, B. E. (1999) Strategic Brand Communication Campaigns. Lincolnwood (Chicago), Illinois, USA: NTC Business Books

[41] Urban, G. L. (2004) The Emerging Era of Customer Advocacy". MIT Sloan Management Review, 45 (2)

[42] Yang, Y. (2010) The Construction to Brand Culture Based on Corporate Culture. International Journal of Business Management, 5 (4) 223-226

[43] Zutchi, A., \& Sohal, S. A. (2005) Integrated Management System: the Experience of Three Australian Organizations. Journal of Manufacturing Technology Management, 16 (2) 211-232 